\title{
Exercise induced bronchospasm in Ghana: differences in prevalence between urban and rural schoolchildren
}

Emmanuel O D Addo Yobo, Adnan Custovic, Simon C O Taggart, A P Asafo-Agyei, Ashley Woodcock

\begin{abstract}
Background - As more developing countries adopt a westernised style of living, an increase in the prevalence of asthma can be expected to occur in these areas. A study was undertaken to establish the normal response to exercise in Ghanaian children and to use these normal values to determine the prevalence of exercise induced bronchospasm (EIB) in urban rich (UR), urban poor (UP), and rural (R) school children. Skin test reactivity to common inhalant allergens in UR, UP, and $R$ children with and without EIB was also investigated.
\end{abstract}

Methods - Two hundred children aged 9-16 years without a previous history of respiratory symptoms were randomly selected and underwent free running exercise testing. A normal response to exercise was defined as the group mean change in peak expiratory flow rate (PEFR) \pm 2 standard deviations. This value was used to identify the prevalence of EIB in UR, UP, and $R$ schoolchildren. A total of 1095 children from three different schools underwent exercise testing (220 UP, 599 UR, 276 R), after which 916 children underwent skin prick testing to six common inhalant allergens ( $D$ farinae, $D$ pteronyssinus, cat, dog, Aspergillus flavus and Candida albicans).

Results - From the results of exercise testing in asymptomatic children the normal range was defined as a fall in PEFR of $<12.5 \%$ after exercise. Thirty four children were classified as having EIB on the basis of the above definition, giving an overall prevalence of $3.1 \%$. The prevalence of EIB was significantly higher in UR children $(4.7 \%)$ than in both UP $(2.2 \% ; p<0.05)$ and $R$ children $(1.4 \% ; p<0.01)$. However, the prevalence rates in the UP and $R$ children were similar. The prevalence of atopy in the whole population was $4.4 \%$. Of the children with EIB, $10 \%$ were skin test positive to at least one of the allergens tested. The prevalence of atopy was significantly higher in UR children $(6.55 \%, 95 \%$ confidence interval (CI) $4.5 \%$ to $9.2 \%$ ) than in UP $(2.9 \%, 95 \%$ CI $0.9 \%$ to $6.7 \%)$ and $R$ children $(1.5 \%, 95 \%$ CI $0.4 \%$ to $3.7 \%)$, respectively $(\mathbf{p}<0.005)$.

Conclusions - The prevalence of EIB and atopy is higher in urban rich than in urban poor or rural children suggesting that, in addition to genetic predisposition, social and environmental factors such as wealth, life style, and housing are important determinants of these phenotypes.

(Thorax 1997;52:161-165)

Keywords: exercise induced bronchospasm, atopy, asthma, prevalence, urban, rural.

Prevalence rates for childhood asthma from different parts of the world are increasing in spite of effective treatment being available. ${ }^{1-8}$ Studies from around the world have allowed comparisons of the prevalence of asthma to be made between different countries and, in particular, between different life styles. ${ }^{910} \mathrm{~A}$ number of studies from developing countries suggest that the prevalence of asthma is lower than in developed countries. ${ }^{7112}$ Regional differences in asthma prevalence within developing countries have been described ${ }^{1314}$ where the prevalence in urban communities seems to be much higher than in those living rurally. ${ }^{1314}$ Atopy is a major risk factor for the development of asthma ${ }^{1516}$ but previous studies have suggested that the prevalence of atopy in subSaharan Africa is low. ${ }^{111718}$

Exercise testing is an objective method of confirming exercise induced bronchospasm (EIB) and has been used in several epidemiological studies of the prevalence of asthma in different countries. ${ }^{131419}$ However, different studies have used different definitions of EIB in estimating its prevalence. ${ }^{20-25}$

Little is known about the current prevalence of either EIB or atopy in West Africa. The aims of this study were therefore to establish the range of normal response to exercise in Ghanaian children, to use these normal values to determine the prevalence of EIB in urban rich, urban poor, and rural schoolchildren, and to investigate the skin test reactivity to common inhalant allergens in urban rich, urban poor, and rural children with and without EIB.

\section{Methods}

STUDY SETTING

The study was carried out during the dry season (February and March) in Kumasi, the second largest city in Ghana with an estimated population of 700000 . The entire city is crowded with light industry and considerable motor vehicle pollution. 
Schools in Kumasi are categorised into urban poor (UP) and urban rich (UR) according to the school fees charged. One school from each category was selected for study on the basis of proximity - Kotei Primary and Junior Secondary schools from the UP category and University of Science and Technology Primary and Junior Secondary schools from the UR category. The third school was selected from a nearby rural area (Ohwim Primary and Junior Secondary schools) on the basis of size and accessibility. The UR and UP schools were situated two kilometres apart and the rural (R) school was situated 20 kilometres away, outside the town.

The study was approved by the Ghana Education Service and the management of the University of Science and Technology Primary and Junior Secondary Schools, Kumasi. Prior to entry into the study parental consent was sought through the heads of the schools concerned.

SUBJECTS

Establishing a normal response to exercise in Ghanaian children

Meanings for words like "asthma", "wheezing", and "chest tightness" vary between different languages and may have different meanings even within the same language. Some of the children and parents in the current study could therefore find it difficult to understand questions from commonly used validated questionnaires, or there could be a considerable difference in the interpretation of different terms used such as "asthma" and "wheezing". It was therefore decided to obtain a careful history of respiratory symptoms (cough, wheeze, or tightness in the chest) by interviewing schoolchildren. All interviews were performed by the same paediatrician experienced in local customs and dialects. Eight hundred and ninety three school children aged between 9 and 16 years from the three schools were interviewed and 628 children without history of any respiratory symptoms were identified. Of these, 200 were randomly selected and underwent exercise testing according to the test protocol. All children were free from upper respiratory tract infections in the four week period prior to the study. A normal response to exercise was subsequently defined as the group mean change in peak expiratory flow rate $(\mathrm{PEFR}) \pm 2$ standard deviations

To ensure consistency all exercise challenge tests were performed by the same investigators.

Prevalence of EIB in urban rich, urban poor and rural schoolchildren

Once the normal value for change in PEFR following exercise was established, it was used to identify the prevalence of EIB in UR, UP, and $\mathrm{R}$ children. A total of 1095 children aged 9-16 were exercised (220 UP, 599 UR, 276 $\mathrm{R})$. All children belonged to the same ethnic pool.
EXERCISE TESTING

The schools were visited in turn on a day to day basis and the children were studied class by class. Absentees were asked to join the next class. Standing height and weight without shoes of all children were measured. Each child was assigned his or her own peak flow meter and its use was demonstrated to the whole group. The children were then allowed to practise in groups of five until good technique was achieved (blowing through the meter from the peak of deep inspiration with maximum effort and without any air leaks from around the mouth piece until three readings less than 5\% apart were consistently achieved). Readings were recorded as the best of three blows in a row. At the beginning of the test the PEFR was recorded and compared with age/height predicted data. If the PEFR was less than $60 \%$ of predicted the exercise test was not performed.

Exercise provocation consisted of free running outdoors for six minutes at a jogging pace aiming at a heart rate of more than 170 beats/ min or $85 \%$ maximum for age, whichever was greater. ${ }^{20}$ The PEFR manoeuvre was then repeated five and eight minutes after the exercise and the best of three readings was recorded. The lower PEFR recorded at five or eight minutes was taken as the final PEFR after exercise. All children who had a fall in PEFR of $12.5 \%$ or more received salbutamol and rested for 10 more minutes.

Tests were carried out between 08.00 hours and 12.00 hours on each day. Relative humidity was recorded as the daily mean between 06.00 hours and 12.00 hours and temperature as the daily mean.

SKIN TESTING

At the completion of the exercise test children underwent skin prick testing to six common inhalant allergens (Dermatophagoides farinae, Dermatophagoides pteronyssinus, cat, dog, Aspergillus flavus, Candida albicans with histamine and saline as controls; Allergopharma, Germany). A total of 916 children and parents gave consent to be skin tested. A positive reaction was defined as a weal of mean diameter at least $3 \mathrm{~mm}$ greater than the negative control. Atopy was defined as a positive response to at least one of the allergens used.

\section{Results}

The mean morning temperature and relative humidity for the period of study were $28^{\circ} \mathrm{C}$ and $60 \%$, respectively, with little day to day variability.

ESTABLISHING NORMAL RESPONSE TO EXERCISE In 200 previously asymptomatic children the mean (SD) fall in PEFR was 2.69 (4.96)\%. The normal distribution of the data was confirmed by the $\chi^{2}$ test. Values of more than two standard deviations from the mean were 
Table 1 Prevalence of exercise induced bronchospasm (EIB) in different age groups and positive skin tests in urban rich, urban poor, and rural schoolchildren

\begin{tabular}{llll}
\hline & $\begin{array}{l}\text { Prevalence of EIB } \\
(9-12 \text { years) }\end{array}$ & $\begin{array}{l}\text { Prevalence of EIB } \\
(13-16 \text { years) }\end{array}$ & $\begin{array}{l}\text { Prevalence of positive } \\
\text { skin tests }\end{array}$ \\
\hline Urban poor & $2.2 \%$ & $0 \%$ & $2.9 \%$ \\
$(\mathrm{n}=220)$ & $(3 / 139)$ & $(0 / 81)$ & $(5 / 172)$ \\
Urban rich & $4.7 \%$ & $3.1 \%$ & $6.5 \%$ \\
$(\mathrm{n}=599)$ & $(19 / 406)$ & $(6 / 193)$ & $(31 / 473)$ \\
Rural & $2.7 \%$ & $1.6 \%$ & $1.5 \%$ \\
$(\mathrm{n}=276)$ & $(4 / 148)$ & $(2 / 128)$ & $(4 / 271)$ \\
Total & $3.8 \%$ & $2.0 \%$ & $4.4 \%$ \\
& $(26 / 693)$ & $(8 / 402)$ & $(40 / 916)$ \\
\hline
\end{tabular}

considered abnormal. Using this criterion the normal value was defined as $<12.5 \%$ fall in PEFR after exercise.

PREVALENCE OF EIB IN UR, UP, AND R SCHOOLCHILDREN

All children who had a fall in PEFR after exercise of more than $12.5 \%$ were classified as having EIB.

A total of 1095 children were exercised. One child in the rural area was not allowed to run because of severe sickle cell anaemia and was excluded from the study. No child was excluded because of a low baseline PEFR.

The mean (SD) age of the three groups did not differ (UP 11.8 (1.8) years, UR 11.5 (1.8) years, $R 12.1$ (2.0) years; $p>0.1$ ) but children in the UR group were heavier and taller than those in the UP and R groups in all age groups $(\mathrm{p}<0.05)$. Thirty four children (16 boys) were classified as having EIB, giving an overall prevalence of $3.1 \%$ and a male:female ratio of 1 : 1.3. Table 1 shows the prevalence of EIB by age in the UR, UP, and R schools. The prevalence of EIB was significantly higher in UR children than in UP $(\mathrm{p}<0.05)$ and $\mathrm{R}$ children $(p<0.01)$. However, the prevalence rates in the UP and $R$ children were similar ( $p>0.5)$. The younger age group had a higher prevalence of EIB, but the difference between the two age groups was not statistically significant $(\mathrm{p}=$ $0.06)$.

\section{SKIN TESTING}

A total of 916 children underwent skin testing to six common inhalant allergens (table 1), of which 30 had a positive response to exercise. The prevalence of atopy in the whole population was $4.4 \%(40 / 916)$. The results show that $10 \%$ of the children with EIB (3/30) were skin test positive to at least one of the allergens used, all of them showing immediate skin test reactivity to house dust mite (all were skin test positive to $D$ farinae and two to $D$ pteronyssinus). None of the children with EIB was skin test positive to cat or dog. No significant difference in the prevalence of atopy was found between children with and without EIB ( $p>0.1)$, but the prevalence of atopy was significantly higher in UR children $(6.55 \%, 95 \%$ confidence interval (CI) $4.5 \%$ to $9.2 \%)$ than in UP $(2.9 \%$, $95 \%$ CI $0.9 \%$ to $6.7 \%$ ) and R children $(1.5 \%$, $95 \%$ CI $0.4 \%$ to $3.7 \%$ ), respectively $(\mathrm{p}<0.005$; table 1). No significant difference was found between UP and $\mathrm{R}$ children.
None of the children studied showed a positive skin test to dog, Aspergillus flavus and Candida albicans allergens while two children without EIB in the UR school were skin test positive to cat.

\section{Discussion}

Exercise testing is often used as an objective method for the diagnosis of asthma in epidemiological studies..$^{13142326-30}$ However, widely differing and often arbitrary criteria are still used to estimate the normal response to exercise. A fall in PEFR of $10-20 \%,{ }^{22}{ }^{23}$ and even $25 \%,{ }^{24}$ has been considered the limit of the normal response in various studies. It is therefore important to standardise the exercise test by defining the mode of response in the normal population which can then be used to identify those subjects with a greater than normal response to exercise. ${ }^{31-33} \mathrm{~A}$ standard respiratory questionnaire could not be used in this study because it was difficult for the children and parents to understand the questions from commonly used validated questionnaires. Kattan et al established that PEFR and $\mathrm{FEV}_{1}$ were the most sensitive tests and were abnormal in $83 \%$ and $84 \%$, respectively, of those asthmatic children who had a positive exercise test response. ${ }^{26}$ A fall in PEFR of $12.5 \%$ was defined as the lower limit of normal, similar to the results found in this study.

The overall prevalence of EIB in the three areas combined in our study was $3.1 \%$ and was equally distributed between the sexes. Furthermore, the prevalence was significantly greater in the urban rich than in either urban poor or rural areas. The estimates of the prevalence of EIB in other studies using similar methodology have varied greatly between studies in different locations. In a study of 12 year old children in Cardiff the prevalence of a $15 \%$ or more fall in PEFR following six minutes free running was approximately $7 \%$ in 1973 and $8 \%$ in $1988 . .^{30}$ In South Africa, using an arbitrary $15 \%$ drop in PEFR to define exercise induced asthma in a group of 6-9 year old children, ${ }^{14}$ the prevalence of asthma was approximately $3 \%$ in urban children and $0.1 \%$ in rural children. A similar trend in the prevalence of exercise induced asthma was found in urban $(5.8 \%)$ and rural $(0.1 \%)$ Zimbabwean children. ${ }^{13}$ These findings suggest that, in addition to genetic predisposition, social and environmental factors such as wealth, life style, and housing are important determinants in the expression of asthma.

The prevalence of EIB in the UR children in this study is comparable to that found in South Africa and Zimbabwe. ${ }^{1314}$ Our results also suggest that the prevalence of EIB is higher in UR children than in UP children. Differences in the geographical location cannot explain the difference between the urban and rural populations as all children were living in the same climatic conditions and belonged to the same ethnic pool. Differences in life styles, housing, and exposure to indoor allergens or outdoor pollutants may be important. It is reasonable to assume that a rich urban popu- 
lation adopts a more westernised life style and housing than the other communities. This can explain the finding of a similar prevalence of EIB between urban poor and rural children, as the observed differences in proportion of children with EIB probably reflect differing life styles, rather than areas of residence. However, it is important to stress that there was a significant number of children with a positive response to exercise even in the rural population. Although Kumasi is a highly polluted city, it is unlikely that air pollution explains the marked differences in the prevalence of EIB between urban rich and poor children.

The difference in the prevalence of EIB between the rich urban and rural areas, although statistically significant, was not as marked as in the previously mentioned studies in South Africa and Zimbabwe. ${ }^{1314}$ In the study of Zimbabwean children the rural community was situated $150 \mathrm{~km}$ from the urban community and was isolated. The urban and rural areas in our study were separated by about $20 \mathrm{~km}$. It is possible that the relatively short distance allowed migration between these areas, probably contributing significantly to the way of life in the rural area. The results in the Ohwim schools may not reflect what would be found in a truly remote rural locality as some "western" habits could have been adopted in this area.

Sensitisation to indoor allergens is a major risk factor for the development of asthma and maintaining asthmatic symptoms. ${ }^{3435}$ Our failure to show significant differences in the prevalence of atopy between children with and without EIB could reflect insufficient power due to the small number of children who had EIB (30) and were skin tested. However, we found the prevalence of atopy to be significantly higher in UR children than in either UP or R children, which suggests that a "westernised" life style is associated with an increase in IgE mediated sensitisation. This may be due to the increased exposure to indoor allergens such as house dust mite but other factors such as diet, passive smoking, and air pollution may also play a part.

House dust mites are the most important cause of asthma world wide. ${ }^{36}$ Godfrey found house dust mites to be plentiful in rural homes in the Gambia ${ }^{11}$ and this may also apply to Ghana. However, factors such as ventilation, temperature, and the nature of bedding and furnishings may affect the allergen content of the domestic environment. Furthermore, it is possible that mites other than $D$ pteronyssinus and $D$ farinae play an important part in sensitisation in this part of the world - for example, Blomia tropicalis. In Ghana children spend more time outdoors and this might affect their exposure to certain allergens. Pet ownership is considerably less common than in developed countries. It is interesting to note that only two out of 916 children were skin test positive to cat, and none to dog. There is a need to investigate further what are the most important allergic sensitisers in this population. Cockroach and other organic allergens could play an important part in the development of IgE mediated sensitisation and asthma in this part of the world.

In conclusion, the prevalence of EIB and atopy was found to be significantly higher in rich urban children than in poor urban or rural children. This finding suggests that, in addition to genetic predisposition, social and environmental factors such as wealth, life style, and housing are important determinants in the expression of these phenotypes. Further studies of the risk factors for asthma are needed in order to develop strategies for asthma prevention in this population.

The authors thank the Tropical Health and Education Trust, 21 Edenhurst Avenue, London for sponsorship of the study, the head teachers, management, and teachers of the participating schools for their cooperation, and Rita Nketia Daadom and Gloria Doku, nurses in the Komfo Anokye Teaching Hospital, Kumasi, for their help with exercise testing.

1 Gergen PJ, Weiss KB. The increasing problem of asthma in the United States. Am Rev Respir Dis 1992;146:823-4. Burney P, Chinn S, Rona RJ. Has the prevalence of asthma increased in children? Evidence from the national study increased in children? Evidence from the national study

3 Robertson CF, Heycock E, Bishop J, Nolan T, Olinski A, Phelan P. Prevalence of asthma in Melbourne schoolchildren: changes over 26 years. BMF 1991;302:1116-8.

4 Shaw RA, Crane J, O'Donnell TV, Porteous LE, Coleman ED. Increasing asthma prevalence in a rural New Zealand adolescent population: 1975-1989. Arch Dis Child 1990; 65:1319-23.

5 Haahtela T, Lindholm H, Bjorksten F, Koskenvuo K, Laitinen LA. Prevalence of asthma in Finnish young men. BMF 1990;301:266-8.

6 Nishima S. A study of the prevalence of bronchial asthma in school children in western districts of Japan: comparison between the studies in 1982 and 1992 with the same methods and same districts. Arerugi 1993;42:192-204.

7 Leung R, Jenkins M. Asthma, allergy and atopy in southern Chinese school students. Clin Exp Allergy 1994;24:353-8.

8 Luyt DK, Burton PR, Simpson H. Epidemiological study Luyt DK, Burton PR, Simpson H. Epidemiological study
of wheeze, doctor diagnosed asthma and cough in preof wheeze, doctor diagnosed asthma and cough: $1386-90$.

9 Burr ML, Limb ES, Andrae S, Barry DMJ, Nagel F. Childhood asthma in four countries: a comparative survey. Int F Epidemiol 1994;23:341-7.

10 Robertson CF, Bishop J, Sennhauser FH, Mallol J. International comparison of asthma prevalence in children: Australia, Switzerland, Chile. Pediatr Pulmol 1993;16:219 26.

11 Godfrey RC. Asthma and IgE levels in rural and urban communities in the Gambia. Clin Allergy 1975;5:201.

12 Warrel DA, Fawcet IW, Harrison BDW, Agamah AJ, Ibu JJO, Pope HM, et al. Bronchial asthma in the Nigerian Savannah Region. $O$ f Med 1975;174:325.

13 Keeley DJ, Neill P, Gallivan S. Comparison of the prevalence of reversible airway obstruction in rural and urban $\mathrm{Zim}-$ babwean children. Thorax 1991;46:549-53.

14 Van Niekerk CH, Wiebers EG, Shore SC, Heese H de V, Van Dhalkwyk DJ. Prevalence of asthma: a comparative study of urban and rural Xhosa children. Clin Allergy study of urban

15 Smith JM, Disney ME, Williams JD, Goels ZA. Clinical significance of skin reactions to mite extracts in children significance of skin reactions to mite extracts in childre with asthma. BMF 1969;1:723-6.

16 Burrows B, Martinez FD, Halonen M, Barbee RA, Cline MG. Association of asthma with serum IgE levels and skin reactivity to allergens. $N$ Engl f Med 1989;320:271-7.

17 Al-Frayh A. IgE mediated skin reaction among asthmatic children in Riyadh. Ann Saudi Med 1991;2:448-51.

18 Commey JOO, Haddock DRW. Skin sensitivity to house dust mite extracts in Ghanaian asthmatics in Accra. Trans Roy Soc Trop Hyg 1973;67:107.

19 Pierson WE. Exercise-induced bronchospasm in children and adolescents. Pediatr Clin North Am 1988;35:1031-40.

20 Taussig LM, Chernick V, Wood WR, Farrel P, Mellins $R$. Standardization of lung function testing in children. Proceedings and recommendations of the GAP ConProceedings and recommendations of the

21 Johnson NM. Respiratory medicine. London: Blackwell Scientific Publications, 1986:89.

22 Godfrey S, Silverman M, Anderson SD. Problems of interpreting exercise-induced asthma. $\mathcal{F}$ Allergy Clin Immunol terpreting exercise-in

23 Burr ML, Eldridge BA, Borysiewicz LK. Peak expiratory flow rates before and after exercise in school children Arch Dis Child 1974;49:923-6.

24 Cropp GJA. Relative sensitivity of different pulmonary function tests in the evaluation of exercise induced asthma. Pediatrics 1975;56(Suppl):860-7.

25 Kral B, Havel V, Tilser P, Jirkal J, Elias J. Exercise induced bronchoconstriction: a long-term follow up study. Allergol Immunol 1989;5(Suppl):29. 
26 Kattan M, Keens TG, Mellis CM, Levison H. The response to exercise in normal and asthmatic children. $\mathcal{F}$ Pediatr 1978;92:718-21.

27 Godfrey S, Springer C, Noviski N, Maayan Ch, Avital A. Exercise but not methacholine differentiates asthma from chronic lung disease in children. Thorax 1991;46:488-92.

28 Scadding JG. The definition of asthma: general introduction In: Porter R, Birch J, eds. Identification of asthma. London: In: Porter R, Birch J, eds. Identification

29 Anderson SD, Silverman M, Konig P, Godfrey S. Exercise induced asthma. $B r \mathcal{F}$ Dis Chest 1975;69:1-39.

30 Burr ML, Butland BH, Kings S, Vaughan-Williams E. Changes in asthma prevalence: two surveys 15 years apart. Arch Dis Child 1989;64:1452-6.

31 Godfrey S. Bronchodilators in exercise-induced asthma. In: Clark THJ, Cochrane GM, eds. Bronchodilator therapy. Auckland, New Zealand: ADIS Press Ltd, 1984:112-30.
32 Custovic A, Arifhodzic N, Taggart SCO, Woodcock A. Assessing exercise-induced bronchospasm. Chest 1994 105:1624-5.

33 Custovic A, Arifhodzic N, Robinson A, Woodcock A. Exercise testing revisited: the response to exercise in normal and atopic children. Chest 1994;105:1127-32.

34 Colloff MJ, Ayers J, Carswell F, Howarth PH, Merrett TG, Mitchell EB, et al. The control of allergens of dust mites and domestic pets: a position paper. Clin Exp Allergy 1992 22(Suppl 2):1-28

35 Custovic A, Taggart SCO, Francis HC, Chapman MD Woodcock A. Exposure to house dust mite allergens and the clinical activity of asthma. F Allergy Clin Immunol 1996; 98:64-72.

36 Platts-Mills TAE, Thomas W, Aalberse RC, Vervloet D, Chapman MD. Dust mite allergens and asthma: report of a second international workshop. F Allergy Clin Immuno 1993;89:1046-57. 